BMJ Open

Sport \&

Exercise

Medicine

\section{Systematic development of an injury prevention programme for judo athletes: the IPPON intervention}

To cite: von Gerhardt AL, Vriend I, Verhagen E, et al. Systematic development of an injury prevention programme for judo athletes: the IPPON intervention. BMJ Open Sport \& Exercise Medicine 2020;0: e000791. doi:10.1136/ bmjsem-2020-000791

- Supplemental material is published online only. To view please visit the journal online (http://dx.doi.org/10.1136/ bmjsem-2020-000791).

Received 18 March 2020 Revised 25 June 2020

Check for updates

(C) Author(s) (or their employer(s)) 2020. Re-use permitted under CC BY-NC. No commercial re-use. See rights and permissions. Published by BMJ.

For numbered affiliations see end of article.

Correspondence to

Amber L von Gerhardt;

a.vongerhardt@amsterdamumc.nl

\section{ABSTRACT}

Objectives To systematically develop an injury prevention programme in judo and test its feasibility: Injury Prevention and Performance Optimization Netherlands (IPPON) intervention

Methods We used the five-step Knowledge Transfer Scheme (KTS) guidelines. In the first two steps, we described the injury problem in judo and showed possibilities to reduce the injury rates. In the third step, the Knowledge Transfer Group (KTG) translated this information into actions in judo practice. Expert meetings and practical sessions were held. In the fourth step, we developed the injury prevention programme and evaluated its feasibility in judo practice in a pilot study. As a final step, we will evaluate the injury prevention programme on its effectiveness to reduce injuries.

Results In the first two steps, information collected indicated the need for reducing judo injuries due to high incidence rates. Injury prevention programmes have shown to be effective in reducing injuries in other sports. For judo, no injury prevention programme has yet been systematically developed. In the third step, the KTG reached consensus about the content: a trainer-based warm-up programme with dynamic exercises focusing on the shoulder, knee and ankle. In the fourth step, the intervention was developed. All exercises were approved in the pilot study. Based on the pilot study's results, the IPPON intervention was extended and has become suitable for the final step.

Conclusion We developed the IPPON intervention using the systematic guidance of the KTS. This trainer-based programme focuses on the prevention of shoulder, knee and ankle injuries in judo and consists of 36 exercises classified in three categories: (1) flexibility and agility, (2) balance and coordination and (3) strength and stability. The effectiveness and feasibility of the intervention on injury reduction among judo athletes will be conducted in a randomised controlled trial.

\section{INTRODUCTION}

Judo is a Japanese combat sport with approximately 20 million active participants in more than 200 affiliated countries spread over all continents. ${ }^{1}$ There are many health benefits of participating in judo, such as the increase of physical capabilities and mental resilience. ${ }^{2}$ Although the International Judo Federation (IJF) places a large emphasis on athlete safety,

\section{Summary box}

What are the new findings

- A new feasible judo-specific injury prevention programme was developed to reduce and/or prevent the occurrence of musculoskeletal shoulder, knee and ankle injuries in judo using the Knowledge Transfer Scheme.

- The IPPON intervention consists of 12 exercises (choice from 36 unique exercises) lasting approximately $10 \mathrm{~min}$ and performed two times per week.

- Information and instructions about the IPPON intervention are available on photo and description cards, instruction book and instruction videos.

How might it impact on clinical practice

- The effectiveness and feasibility of the IPPON intervention to reduce and/or prevent the occurrence of musculoskeletal injuries in judo needs to be evaluated in a randomised controlled trial among judo athletes.

the injury rates in both competitive and recreational judo are high. ${ }^{3-5}$ The reported incidence of injuries is up to $29 \%$ in elite judo athletes during competition. ${ }^{6}$ Judo injuries are highly prevalent in recreational Dutch judo athletes as well, with up to $41 \%$ of the judo athletes being injured within the 3 preceding months. ${ }^{7}$ These injuries can lead to significant periods of time loss from sports with a negative impact on performance. ${ }^{8}$ Long-term effects of joint injuries increase the risk of osteoarthritis development and joint instability, causing limitations in daily life, sports and/or work. ${ }^{9}$ Thus, injuries in judo could potentially lead to important short-term and long-term problems.

Sport-specific injury prevention programmes in several sports have been proven effective in reducing the rates of sport injuries in both recreational and elite athletes. ${ }^{10-12}$ For individual contact sports as judo, the practical use of these theoretical programmes is difficult due to the following reasons. First, 
these programmes are often developed for team sports. ${ }^{13}$ Second, there is a missing link between theory and judo practice. The practical tool to develop an injury prevention programme that combines theory and practice is the Knowledge Transfer Scheme (KTS). ${ }^{14}$

Up to now, only two judo-specific injury prevention programmes have been described in the literature. ${ }^{15} 16$ Both programmes were not systematically developed using a practical tool, and the feasibility in practice and the effectiveness of these programmes to prevent injuries have not been evaluated yet. Especially, the systematic development process of an intervention for judo based on evidence and practical experience is essential for successful implementation.

Therefore, the aim was to systematically develop an injury prevention programme for judo athletes to prevent musculoskeletal injuries among judo athletes and assess its feasibility in the judo practice in a pilot study. In this paper, we described in detail the development process, preparation and procedures in the run-up to the intervention phase. We hypothesised that we could develop a practically applicable injury prevention programme using the KTS.

\section{METHODS}

The medical ethics committee of the Academic Medical Center Amsterdam granted exempt status (qualified as non-WMO obliged research, W19_071). The study was funded by The Dutch Organization for Health and Research and Development (ZonMw). Patients or the public were not involved in the design, conduct, reporting and dissemination plans of our research.

\section{Development process}

Successful intervention programmes would require theoretical research frameworks combined with practical implementation. ${ }^{17}$ Several research frameworks have been described in the literature. ${ }^{18} 19$ These frameworks focused on knowledge and evidences derived from research; however, these remain silent on practical implementation. The KTS combines theory and practice by integrating existing research frameworks into a practical tool. Therefore, for the development of the Injury Prevention and Performance Optimization Netherlands (IPPON) intervention, we used the KTS. ${ }^{14}$

The KTS described a systematic process to develop injury prevention interventions in sports. The bottomup approach of the KTS takes into account the facilitators and barriers to the implementation of these interventions. This bottom-up approach indicates the involvement of end-users in the process and has been successfully applied in other sports like hockey and tennis. ${ }^{2021}$ The KTS consists of five steps (figure 1).

\section{Step 1: Problem statement}

The injury problem in judo was described in terms of its magnitude, severity, societal importance and societal burden. We searched the literature (search terms-'martial arts', 'judo' and 'injuries') for information about injuries among judo athletes. ${ }^{3-6} 22-24$

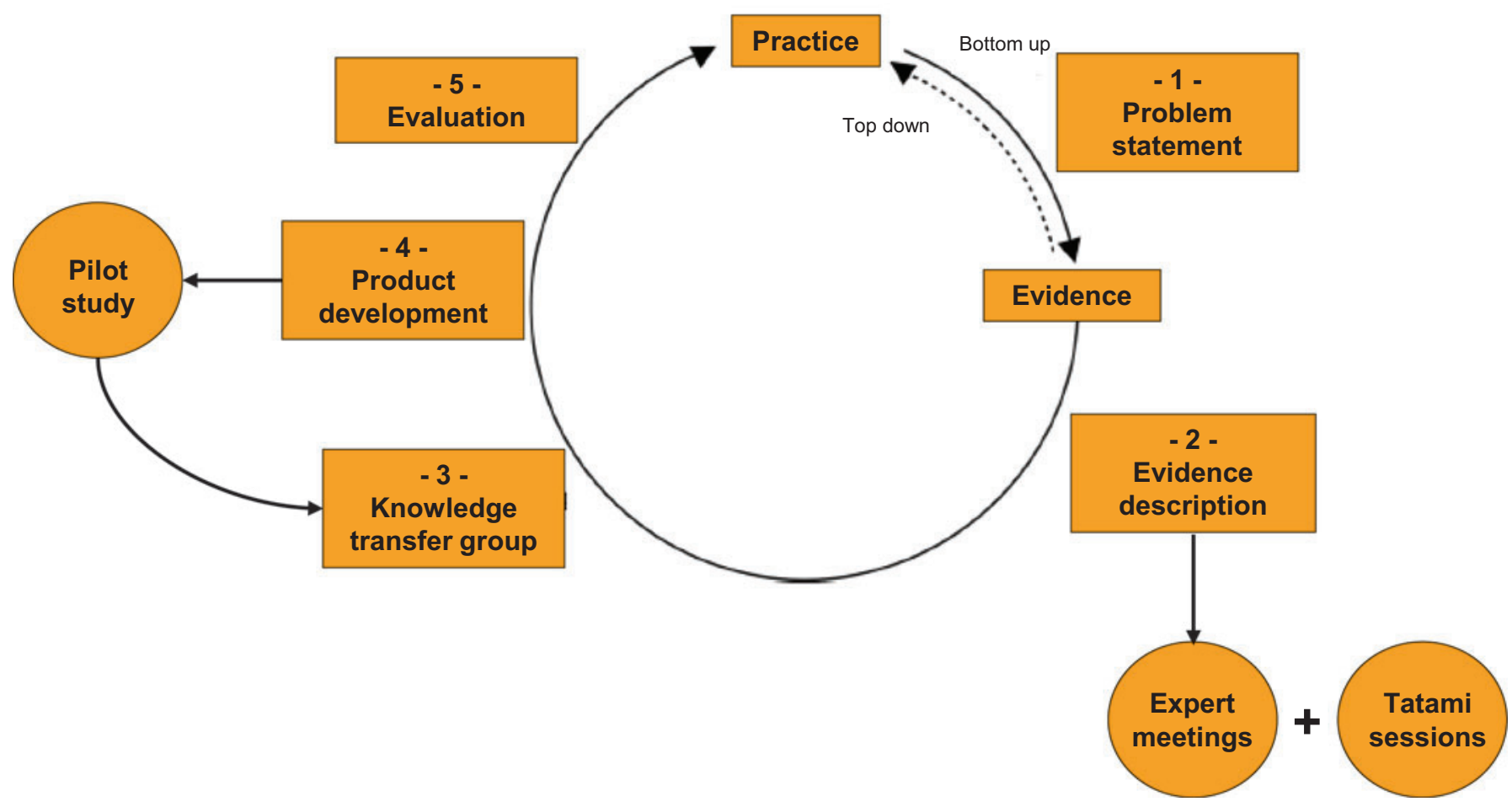

Figure 1 Flow chart of the modified Knowledge Transfer Scheme development process. 


\section{Step 2: Evidence description}

We described available evidence to solve the problem that was postulated in the first step. The literature was searched (search terms-'judo', 'injuries' and 'prevention') for evidence-based injury prevention programmes in judo.

\section{Step 3: Knowledge Transfer Group}

A Knowledge Transfer Group (KTG) was established to translate the information from the first two steps into practical actions. The KTG consisted of key practitioner stakeholders and researchers with expertise on the injury or evidence at hand. Three meetings of 2 hours each were organised with the KTG. In the first KTG meeting, the goals of the intervention were formulated, and potential barriers and facilitators for the adoption and implementation of the intervention were discussed. In addition to the KTS, the coordinating researcher (AvG) met with the judo experts of the KTG individually. The available injury prevention programmes for judo were independently discussed to collect information about the practical use and feasibility of these exercises in daily judo practice. ${ }^{15} 16$ Focus domains for the intervention were determined, and ideas for new exercises were assembled. In the absence of evidence-based judo-specific injury prevention exercises, extra sessions were held in judogi (traditional uniform used for judo practice) on the tatami (judo training ground) to modify existing exercises and add new exercises. Members of the KTG chose their top four exercises for each category and selected the most chosen exercises for inclusion. In the second KTG meeting, the content of the proposed intervention programme was chosen and the concept intervention was delineated.

\section{Step 4: Product development}

We described the development of the injury prevention programme. All information assembled in the previous steps was compiled for the development of the intervention, including exercises and instruction materials. We conducted a 4-week pilot study to determine whether the concept exercises were feasible, could be completed within $15 \mathrm{~min}$ and whether the instruction materials were useful. Trainers were invited to participate with their athletes. Inclusion criteria for judo athletes were as follows: (1) 12 years of age or older, (2) train at least two times per week and (3) capable of speaking and reading the Dutch language. Trainers were instructed by two former elite judo athletes on how to execute the exercises correctly. Photo and description cards, and video instruction recordings of these exercises were available as instruction materials (in Dutch). The athletes performed the trainer-supervised exercises at the start of each training.

For the pilot study

- Trainers were asked to track the performed exercises each training on standardised forms (online supple mental material 1);

- Structured observations were held by the coordinating researcher in the first and the final training session using standardised forms with specific points of interests (online supplemental material 2); and

- At the end of the final training session, the coordinating researcher interviewed all trainers (individual interviews) and all athletes (group interviews). Interviews were held using standardised forms (online sup plemental material 3). Questions to assess the intervention referred to (1) instructions: the use of materials provided; (2) practical use: the structure and sequence of the exercises; (3) usefulness: the adoption and implementation of the intervention in judo practice; (4) time duration: the length of the exercises and warm-up as a whole; and (5) difficulty: the complexity level of the exercises (defined as one, two or three star levels).

In the third KTG meeting, the results of the pilot study were discussed and the intervention programme was modified where appropriate.

\section{Step 5: Evaluation of the intervention}

As a final step, we will evaluate the effectiveness of the injury prevention programme on injury reduction.

\section{RESULTS}

The main findings are summarised in table 1 .

\section{Step 1: Problem statement}

Information collected on the injury problem indicated that an intervention to prevent injuries for judo athletes is needed for recreational and elite athletes. ${ }^{525-29}$ It should focus on the prevention of musculoskeletal injuries in the fingers, shoulder, knee and ankle. ${ }^{2627}$ Trainers and coaches were open to implement the intervention as part of the standard warm-up prior to the training.

\section{Step 2: Evidence description}

Sport-specific injury prevention programmes have shown to be effective in reducing sport injuries. ${ }^{10}$ These warmup programmes generally focus on exercises that aim to improve physical skills of the athlete. In judo, there is a lack of evidence-based prevention programmes that have been tested for feasibility and/or effectiveness. No randomised controlled trials (RCTs) on judo injury prevention strategies were identified.

\section{Step 3: Knowledge Transfer Group}

The multidisciplinary KTG consisted of 14 members (online supplemental material 4). Members had expertise on judo, sports medicine, sports injuries, injury prevention and/or implementation of injury prevention strategies. The expert group consisted of two former judo athletes who participated in the Olympic Games and who are currently working as a sport physician. Two former international judo athletes are current judo trainers. There was one representative of the Dutch judo association. Three sport physicians participated of which one is part of the medical commission of the IJF and was the former union doctor of the Dutch judo association. 
Table 1 Summary of the results categorised by the five-step Knowledge Transfer Scheme guidelines

\begin{tabular}{|c|c|}
\hline Step & Results \\
\hline 1. Problem statement & $\begin{array}{l}\text { Due to the high incidence rates in judo, there is a need for the implementation of an intervention to } \\
\text { prevent injuries among judo athletes. }\end{array}$ \\
\hline 2. Evidence description & $\begin{array}{l}\text { Injury prevention programmes were found effective in reducing injury rates in other sports. For judo, no } \\
\text { prevention programme has yet been systematically developed and no proven effective injury } \\
\text { prevention programme exists. }\end{array}$ \\
\hline $\begin{array}{l}\text { 3. Knowledge Transfer } \\
\text { Group }\end{array}$ & $\begin{array}{l}\text { Unanimous consensus on the design and content of the intervention was reached: } \\
\text { 1. Focus on the prevention of shoulder, knee and ankle injuries. } \\
\text { 2. Trainer-based exercise programme to increase adherence. } \\
\text { 3. Including dynamic exercises performed with a partner. } \\
\text { 4. Choice from different exercises. } \\
\text { 5. } 10-15 \text { min programme. } \\
\text { 6. Exercises performed as warm-up prior to the judo training. } \\
\text { 7. Exercises performed barefoot on the tatami* }\end{array}$ \\
\hline $\begin{array}{l}\text { 4. Product } \\
\text { development }\end{array}$ & $\begin{array}{l}\text { Pilot study: Although all exercises were approved by experts and end-users, the programme was } \\
\text { extended with three strength exercises. } \\
\text { Intervention: } 36 \text { exercises divided in the categories 'flexibility and agility', 'balance and coordination' } \\
\text { and 'strength and stability'. } 12 \text { exercises per category with } 3 \text { levels of difficulty. Use of } 4 \text { exercises per } \\
\text { category and } 12 \text { exercises in total as warm-up routine. }\end{array}$ \\
\hline 5. Evaluation & $\begin{array}{l}\text { The effectiveness and feasibility of the Injury Prevention and Performance Optimization Netherlands } \\
\text { intervention will be evaluated in a randomised controlled trial. }\end{array}$ \\
\hline
\end{tabular}

*Tatami: judo training ground.

There was one orthopaedic surgeon specialised and experienced in judo injuries. Two human movement scientists with knowledge about injury prevention participated. Two representatives of the Dutch consumer safety institute with expertise on implementation of injury strategies were involved. Furthermore, the coordinating researcher is an international former judo athlete.

In the first KTG meeting, the possibilities of reducing injury rates in judo athletes were discussed. Potential facilitators were identified for the adoption and implementation of a judo-specific trainer-based injury prevention programme. Potential facilitators might be a general respect towards the trainer by athletes, and the standard warm-up period at the start of each judo training. Potential barriers might be the long-term structural implementation and the various ideas of trainers about the warm-up.

As a sidestep of the KTS, the coordinating researcher discussed the content of the two available interventions through individual meetings with five judo experts. ${ }^{15} 16$ The opinion of the judo experts was that relatively few exercises were dynamic and variation could be improved, and as such, exercises were not fully in line with daily judo practice. The basic principles of some exercises were found to be useful for the development of our prevention programme, on condition that modifications were applied. These exercises include lunches, hop exercises, o-soto-gari exercise, plank exercises, the superman, the pump walk and squat exercises. Three extra brainstorm sessions were held in judogi on the tatami to modify these exercises and to create new exercises. These sessions were held with three judo experts. Each brainstorm session was led by the coordinating researcher. All exercises were filmed. All members of the KTG received the videos and provided feedback about the potential preventive effect and the practical use of the exercises in judo. Members of the KTG independently rated the exercises on these aspects before the start of the second KTG meeting.

In the second KTG meeting, members of the KTG selected the highest rated exercises to include in the programme and the lowest rated exercises to exclude from the programme. In cases of doubt, the KTG discussed until unanimous consensus was reached. The expert group preferred the following characteristics, with regard to the content and form of the exercises of the new intervention programme: (1) exercises focusing on the prevention of shoulder, knee and ankle injuries. Finger injuries are not included due to the minor severity; (2) a trainer-based exercise programme to increase adherence as judo athletes offer respect and obey the judo trainer; (3) dynamic exercises performed with a partner to create real judo circumstances and to preserve the pleasure in performing the warm-up; (4) multiple options in exercises, so that trainers have autonomy in deciding which exercises to perform each judo training; (5) a duration of $10 \mathrm{~min}$ with a maximum of $15 \mathrm{~min}$. Each exercise lasting no longer than 1 min; (6) exercises performed as warm-up prior to the judo training; (7) exercises performed barefoot on the tatami.

The KTG reached unanimous consensus on the content of the intervention and categorised all exercises by their aim (increasing three different aspects of physical fitness) and three difficulty levels.

\section{Step 4: Product development}

The concept intervention named the IPPON intervention consisted of 33 exercises in total. Trainers were instructed to select 11 exercises in total for each warm-up: 
1. Balance and coordination: this category consisted of 12 exercises. During each training, athletes were instructed to perform four exercises from this category.

2. Flexibility and agility: this category consisted of 12 exercises. During each training, athletes were instructed to perform four exercises from this category.

3. Strength and stability: this category consisted of nine exercises. During each training, athletes were instructed to perform three exercises from this category.

\section{Evaluation of the concept intervention}

The exercises were evaluated on its feasibility at three different judo schools by three different trainers and a total of 34 judo athletes (21 men and 13 women, age range 12-52 years) during a period of 4 weeks. The participants were instructed to perform the programme two times per week over the 4-week time period.

\section{Outcomes of the observations}

There was sufficient space in the dojos (judo training hall) to perform all exercises. The explanations of the exercises from trainer to athletes were clear and correct. Exercises were not always performed as intended. The trainers did not always correct the athletes adequately, while there was a substantial observed difference between athletes in execution of the exercises.

\section{Outcomes of the structured interviews General}

Strong components were that trainers were enthusiastic to use the IPPON intervention as warm-up on a regular basis in judo practice. Trainers mentioned as positive elements the structured design, pleasure for the athletes and the inclusion of exercises targeting all muscle groups. Athletes were also enthusiastic to perform the exercises of the IPPON intervention because of the challenging exercises. Items for improvements were that trainers and athletes missed a cardiovascular warm-up at the start of the programme, falling techniques and they suggested to include more strength exercises.

\section{Instructions}

The photo and description cards, and the instruction video were considered as helpful and relevant by the trainers. Trainers suggested an instruction book with multiple images, more extensive text explanations and the denotation of key points as possible improvements.

\section{Practical use}

Trainers found the rank order of the included exercises logical for the warm-up. All exercises with a partner were preferred to be at the end of the intervention. This also applies for the big jump exercises (eg, ice-skating exercises). Trainers noticed that both low-level and high-level athletes could perform the exercises.

\section{Usefulness}

The opinion of the trainers was that all exercises were potentially preventive for reducing injuries. Trainers preferred more variation of the exercises and the possibility to introduce additional exercises. Athletes mentioned that all muscle groups were sufficiently addressed performing the intervention, especially the shoulders and the lower extremity.

\section{Time duration}

The duration of the warm-up did not exceed $15 \mathrm{~min}$, as timed by the trainers. All exercises were well timed in 1 min as intended.

\section{Difficulty}

All exercises were rated by the athletes on difficulty, ranging from 0 (extremely difficult) to 10 (extremely easy), with 5 indicating a perfect level of difficulty. Exercises in the balance and coordination category had a median of 5 (range 1-9), which indicates a perfect level of difficulty. Exercises in the flexibility and agility category had a median of 4 (range 1-7), which indicates that the exercises are slightly difficult. Exercises in the strength and stability category had a median of 5 (range $3-7$ ), which indicates a perfect level of difficulty.

\section{Modification of the IPPON intervention}

The results of the pilot study were discussed in the third KTG meeting. Based on these results, the KTG formulated modifications in terms of thermoregulation and falling techniques, variation, sequence and difficulty of exercises.

\section{Thermoregulation and falling techniques}

Trainers were instructed to start with running exercises for thermoregulation to increase the heart rate, blood flow and lung ventilation, and falling techniques (ukemi-waza) to improve falling skills prior to the intervention exercises. ${ }^{30} 31$

\section{Variation}

Three additional strength exercises were added to equalise the number of exercises in each category as suggested by trainers. In addition to the new minimum of 12 exercises as part of the IPPON intervention, trainers could add their own exercises if their training requires additional warm-up exercises.

\section{Sequence}

The three categories of exercises were retained, although the order of the first two categories (balance and coordination and flexibility and agility) was switched. All duo exercises were scheduled at the end of the programme. Instructions were added for trainers to select four exercises per category. The numbering of the exercises was removed, as this was wrongly interpreted as the order of exercises. More variation within the programme was created through the requirement of including two exercises for the lower extremity and two exercises for the upper extremity in the balance and coordination category.

\section{Difficulty}

All exercises were reassessed on difficulty by members of the KTG, rated by one star (easy), two stars (moderate) or three stars (difficult). Trainers were instructed to choose 
a difficulty level of the exercises in line with the capacities of the group of judo athletes.

\section{Final IPPON intervention}

The final version of the IPPON intervention (figure 2) consisted of 36 exercises divided into three categories: (1) 'flexibility and agility' subdivided in exercises for the lower and upper extremity, (2) 'balance and coordination' and (3) 'strength and stability'. Each category consisted of 12 exercises with three different levels of difficulty. Trainers were instructed to use 4 exercises per category and 12 exercises in total as a warm-up. These exercises focused on the prevention of shoulder, knee or ankle injuries. Trainers were instructed to start with running exercises and falling techniques prior to the intervention exercises. Available instruction materials were photo and description cards, instruction books and instruction videos (online supplemental material 5).

\section{Step 5: Evaluation of the intervention}

The effectiveness and feasibility of the final IPPON intervention will be evaluated in an RCT (NL7698 trialregister. $\mathrm{nl})$. Judo athletes will use the IPPON intervention as warm-up during the season 2019/2020. All injuries will be registered with online questionnaires during a 6 -month period. The IPPON intervention will be compared to usual warm-up during judo training. International implementation is planned, if the IPPON intervention is proven effective in preventing and/or reducing injuries in judo.

\section{DISCUSSION}

We described the systematic development of an injury prevention programme for judo. All exercises of the IPPON intervention were positively assessed by trainers and athletes in a pilot study with regard to usefulness, practical use, instructions, duration and difficulty. Three strength exercises were added based on the outcomes of the pilot study.

\section{Development process}

For the first step in the development process, we searched the literature to formulate the injury problem in judo. The reported incidence of injuries in judo varied from $11 \%{ }^{25}$ to $29 \%{ }^{6}$ The 3-month prevalence in Dutch recreational judo athletes was $41 \%{ }^{7}$ The highest injury rates were finger $(30 \%)$, knee $(26 \%)$, shoulder $(22 \%)$ and ankle injuries (14\%). ${ }^{26} 27$ The most frequent injury types were ligament sprains, muscle strains and contusions. The most common injury mechanism was being thrown during standing fights (tachi-waza) (85\%), of which the majority were acute injuries. Training injury rates were higher $(70 \%)$ than the competition injury rates. ${ }^{28}$ Injuries in judo cause absence of training and competitions that varied from 1 to 29 days. ${ }^{427} 29$

For the second step in the development process, we searched the literature for injury prevention programmes in judo. In 2014, the Judo 9+ injury prevention programme was published. ${ }^{15}$ This programme consisted of nine exercises to address balance, dynamic stabilisation and core stability. In 2015, the Flemish Judo Association (Belgium) introduced an injury prevention programme for judo athletes. ${ }^{16}$ This expert opinion-based programme consisted of five dynamic and five static exercises with a progression in difficulty. Both programmes have not been tested for their feasibility or effectiveness yet.

Modifications to the IPPON intervention were made after completing the pilot study. The literature supported the need expressed by trainers and athletes to increase the body temperature prior to the intervention exercises $^{30}$ and to improve falling skills as most injuries in judo are associated with the lack of falling skills. ${ }^{31}$ Further, we created an instruction book, improved the photo and description cards and renewed the instruction videos to ensure that all exercises are performed correctly.

\section{Injury prevention programmes across sports}

The practice- and evidence-based IPPON intervention for judo has many similarities with other proven effective interventions. Evidence-based injury prevention programmes have been developed in several sports like football, rugby and basketball. ${ }^{10} 1113$ Effectiveness studies on injury prevention programmes have commonly been conducted in team sports. ${ }^{10} 1113$ The BokSmart Safe Six intervention is an injury prevention programme developed to reduce injuries in the lower extremity and the shoulder among rugby players. ${ }^{32}$ Comparable to our exercises, these exercises focus on increasing strength, stability and balance. These elements are also comparable to the exercises in the FIFA 11+ intervention programme. ${ }^{12}$ The FIFA $11+$ is an injury prevention programme developed to reduce injuries among football players aged 14 years and older. It consists of 15 exercises focus on increasing strength, plyometrics and balance. RCTs showed a decrease in injuries of $50 \%$ among male players and $35 \%$ among female players. ${ }^{12}$

Effectiveness studies on injury prevention programmes in individual sports are limited. Available RCTs conducted among running athletes did not reduce injury rates. ${ }^{33-35}$ These programmes contained elements of static stretching or off-season exercises. Static stretching has not been proven effective. ${ }^{36}$ Implementation of in-season prevention is essential for injury prevention. ${ }^{13}$ Hence, the fundamentals of these exercises are different compared to our intervention. Another difference is that there is, in general, no adequate supervision of the exercises in individual sports. Although judo is an individual sport, all training is supervised by a trainer or coach. Coach-based interventions raise the adherence, which is important for successful implementation. ${ }^{37} 38$

\section{KTS methodology}

The methodology for the development of the IPPON intervention was guided by the KTS. ${ }^{14}$ The KTS has been designed for the direct translation of evidence into practice in sports injury prevention. This methodology 
Amsterdam UMC Universitair Medische Centra

\section{Warm-up programme}

FLEXIBILITY \& AGILITY

Choose 4 exercises
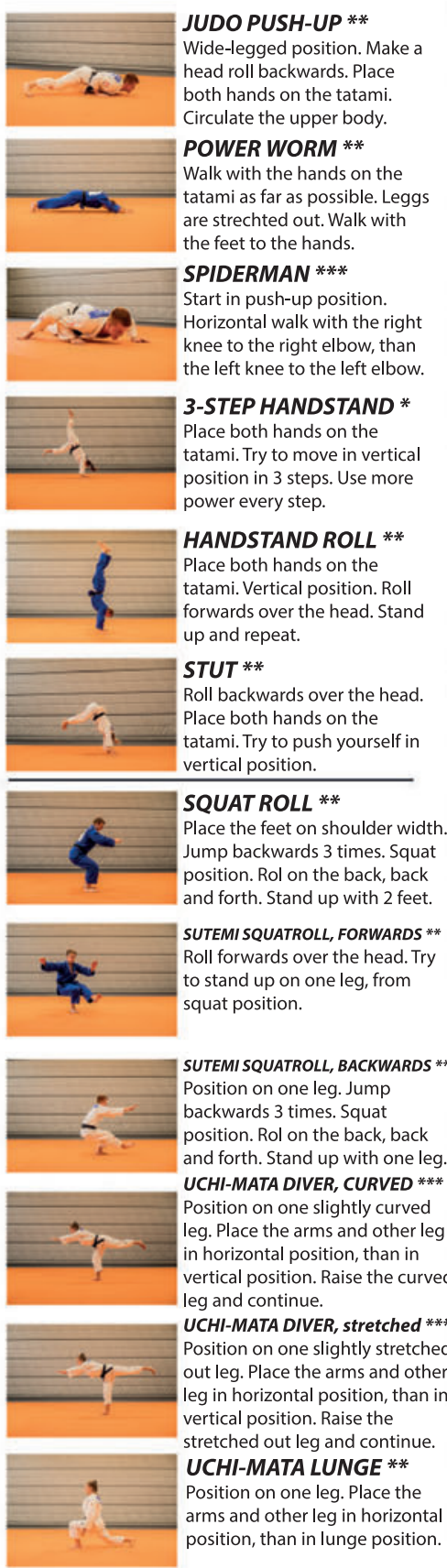

veiligheid $\rightarrow \mathrm{nl}$ JESICAGAL

\section{COORDINATION}

Choose 4 exercises

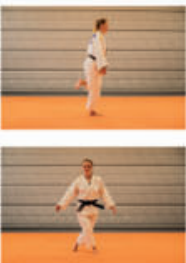

WAVE JUMP*

Place the feet on the tatami.

Jump forwards with 2 feet, than jump forwards with 1 foot while the other leg is curved. Switch.

\section{CROSS JUMP *}

Place the feet on the tatami. Jump forwards and cross both feet. First the right foot in front of the left foot, than switch feet.

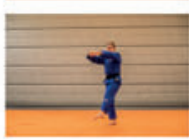

\section{O-UCHI-HOP**}

Place the left foot on the tatami. Stetched out both arms. Circulate clockwise with the right foot. Jump forwards with the left leg.

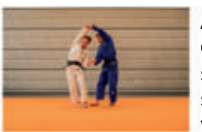

SODE TWIST

Choose a partner. Hold the sleeves crossed. Step 3 times sideways. Turn 360 degrees on your own axis and continue.

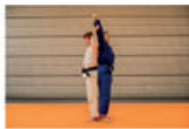

SODE BACKWALK**

Choose a partner. Hold the sleeves crossed. Turn 180 degrees on your own axis. Move sideways in a straight line over the tatami.

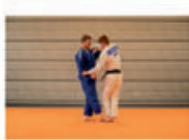
BARAI TWIST**

Choose a partner. Hold the sleeves. Move sideways. Sweep the foot from the partner 3 times, than tu 360 degrees on your own axis.

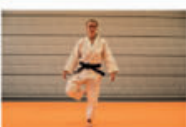
FOOT SALSA *

Walk forwards. Tap the left foot with the right hand. Tap the righ foot with the left hand. Repeat behind the back.

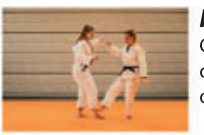

Choose a partner. Tap each others feet. Always start with the outside of the right foot.

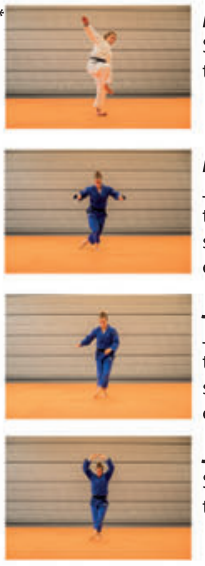

FOOT SALSA BALANCE**

Stretch out both arms and repeat the exercise 'FOOT SALSA'

\section{ICESKATE JUMP **}

Jump sidewards from the left leg to the right leg. Curve the supporting leg. The other leg crosses behind.

\section{JUDO JUMP*}

Jump sidwards from the left leg

to the right leg. Curve the

supporting leg. The other leg corsses in front.

JUDO JUMP BALANCE *** Stretch out both arms and repeat the exercise 'JUDO JUMP'

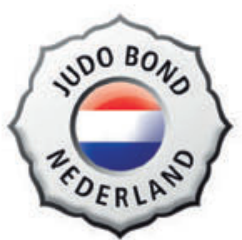

\section{STRENGTH \& \\ STABILITY}

\section{FOOT SALSA DUO **}

Questions? Please contact medical researcher A.L. (Amber) von Gerhardt via a.vongerhardt@amsterdamumc.nl or call +31205662474
WHEELBARROW WALK** Choose a partner. Wheelbarrow position. Walk 3 steps forwards. The partner let loose one leg for WHEELBARROW PUSH ** Choose a partner. Wheelbarrow position. Walk 3 steps forwards. 1 backwards.

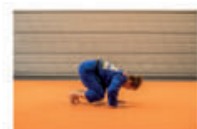
on the tatami. Move head and shoulders up and down towards the tatami. Make a head roll.

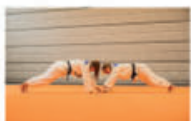

TAP GAME *

oose a partner. Start in push-up position. Try to tap the back of each others hand. It is PULL GAME **

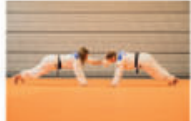

Choose a partner. Start in push-up position. Hold the leeves crossed. Try to pull each MIRROR GAME ***

\section{Choose a partner. Start in} push-up position. Lift in turns a body part of choice. The partner imitate all movements.

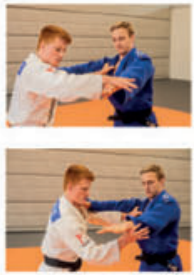

Choose a partner. Hold the sleeves on top. Move over the tatami. Try to push the stretched KATA PULL **

\section{Choose a partner. Hold the} sleeves down below. Move over the tatami. Try to pull the stretched out arms of the partner.

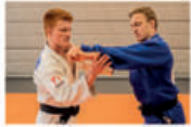
and the revere. Move over the tatami. Try to move the stretched out arm of the parnter.

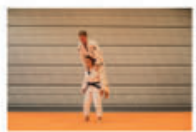
KATA POSITION *

Start position behind the partner with both hands on their shoulders Jump and push yourself up. Stretch out the arms for 5 seconds.

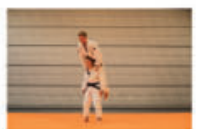

\section{KATA RUN *}

Repeat the exercise 'KATA POSITION', but now the partner and correct yourself.

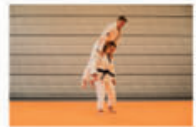

Repeat the exercise'KATA RUN', but now the parter turns 360 degrees on their own axis. push-up with both elbows

Squat position. Place both hands

Choose a partner. Hold the sleeve walks in lines. Try to stay vertical

Figure 2 The final version of the Injury Prevention and Performance Optimization Netherlands intervention. 
has previously been used for the development of a tennisspecific injury prevention programme for tennis players (TennisReady). ${ }^{20}$ TennisReady consists of an on-court and off-court warm-up programme based on cardiovascular, neuromuscular and tennis-specific exercises. The content of those exercises corresponds to the exercises in our programme. We start with cardiovascular management and continue with neuromuscular exercises and judo-specific exercises in three different domains.

In our hypothesis, we asserted that we could develop a practically applicable injury prevention programme using the KTS. We succeeded in systematically developing an injury prevention programme for judo tested in a pilot study. The most important results were the eagerness of trainers and athletes, the perceived usefulness and the correct level of difficulty. Based on these results, the intervention is suitable for evaluation of its effectiveness to reduce injuries. Using the KTS for this process resulted in strengths as well as some limitations.

\section{Strengths}

The strengths of the KTS are the use of a bottom-up approach for the development of the intervention. Interventions are developed using evidence-based information and practical experience to increase effectiveness, which is important for successful implementation. Representation of practice was guaranteed by the multidisciplinary KTG, and by the expertise and experience of end-users participating in the pilot study. The multidisciplinary KTG had a key role in the translation of evidence into practice actions. All 14 members of the KTG contributed to their specific expertise and/or experience.

\section{Limitations}

There were some limitations in the process using the KTS guidelines. The second step of the KTS (evidence description) describes the available scientific evidence to determine the advantage of the intervention. Available evidence on effective injury prevention programmes in other sports and on the prevention of the most frequent injuries in judo was used in the KTS process. ${ }^{12} 3940$ As no evidence was available on the effectiveness of injury prevention strategies in judo, evidence was collected through expert opinions during individual and group meetings. Another limitation in the fourth step of the KTS (product development) is a missing re-evaluation of the adjusted exercises, based on outcomes of the pilot study. However, the KTG considered the changes so minor that reevaluation was not required.

\section{CONCLUSION}

We developed a judo-specific injury prevention programme (IPPON intervention) using the systematic guidance of the KTS by means of experts, aimed to prevent and/or reduce the occurrence of shoulder, knee and ankle injuries among judo athletes. The trainer-based intervention consists of 36 exercises classified into three categories: (1) flexibility and agility, (2) balance and coordination and (3) strength and stability. The programme should be performed minimal two times per week at the start of the judo training. The development of this judo-specific injury prevention programme is the preliminary step in solving the injury problem. The effectiveness and feasibility of the final IPPON intervention on injury reduction among judo athletes should be demonstrated before wide-scale implementation.

\section{Author affiliations}

${ }^{1}$ Amsterdam UMC, University of Amsterdam (UvA), Department of Orthopaedic Surgery, Amsterdam Movement Sciences (AMS), Amsterdam, The Netherlands ${ }^{2}$ Academic Center for Evidence-Based Sports Medicine (ACES), Amsterdam UMC, Amsterdam Movement Sciences (AMS), Amsterdam, The Netherlands

${ }^{3}$ Amsterdam Collaboration on Health and Safety in Sports (ACHSS), Amsterdam UMC IOC Research Center of Excellence, Amsterdam, The Netherlands

${ }^{4}$ Department of Public and Occupational Health, Amsterdam UMC, VU University, Amsterdam Movement Sciences (AMS), Amsterdam, The Netherlands

Twitter Evert Verhagen @evertverhagen, Johannes L Tol @JItol and Gino M M J Kerkhoffs @KerkhoffsG.

Acknowledgements Special thanks to all experts involved in the development of the intervention: Benny van den Broek, Arnold Brons, Jessica Gal, Vincent Gouttebarge, Ronald Joorse, Ellen Kemler, Kai Krabben and Jeroen Mooren. Also, thanks to all judo trainers and judo athletes for their participation in the pilot study.

Contributors All authors were involved in the development of the programme. AVG was responsible for drafting the manuscript. All authors reviewed and agreed on the manuscript.

Funding This study was financially supported by The Dutch Organization for Health Research and Development (ZonMw) with project number 50-53600-98-112.

\section{Competing interests None declared.}

Ethics approval The medical ethics committee of the Academic Medical Center Amsterdam granted exempt status (qualified as non-WMO obliged research, W19_071). The study protocol was registered in the Dutch trial register (NTR 7698).

Provenance and peer review Not commissioned; externally peer reviewed.

Data availability statement All data relevant to the study are included in the article or uploaded as supplemental information.

Supplemental material This content has been supplied by the author(s). It has not been vetted by BMJ Publishing Group Limited (BMJ) and may not have been peerreviewed. Any opinions or recommendations discussed are solely those of the author(s) and are not endorsed by BMJ. BMJ disclaims all liability and responsibility arising from any reliance placed on the content. Where the content includes any translated material, BMJ does not warrant the accuracy and reliability of the translations (including but not limited to local regulations, clinical guidelines, terminology, drug names and drug dosages), and is not responsible for any error and/or omissions arising from translation and adaptation or otherwise.

Open access This is an open access article distributed in accordance with the Creative Commons Attribution Non Commercial (CC BY-NC 4.0) license, which permits others to distribute, remix, adapt, build upon this work non-commercially, and license their derivative works on different terms, provided the original work is properly cited, appropriate credit is given, any changes made indicated, and the use is non-commercial. See: http://creativecommons.org/licenses/by-nc/4.0/.

\section{ORCID iDs}

Amber L von Gerhardt http://orcid.org/0000-0002-1226-1991

Ingrid Vriend http://orcid.org/0000-0001-9605-4019

Evert Verhagen http://orcid.org/0000-0001-9227-8234

Johannes L Tol http://orcid.org/0000-0001-5322-8445

Gino M M J Kerkhoffs http://orcid.org/0000-0001-5916-7049

\section{REFERENCES}

1 IJF (International Judo Federation). Available http:/www.ijf.org/ (accessed on 18 Jun 2019)

2 Torres-Luque G, Hernández-García R, Escobar-Molina R, et al. Physical and physiological characteristics of judo athletes: an update. Sports 2016;4:20. 
3 Kim KS, Park KJ, Lee J, et al. Injuries in national olympic level judo athletes: an epidemiological study. $\mathrm{Br} J$ Sports Med 2015;49:1144-50.

4 Souza M, Monteiro H, Del Vecchio F, et al. Referring to judo's sports injuries in São Paulo State Championship. Sci Sport 2006;21:280-4.

5 Akoto R, Lambert C, Balke M, et al. Epidemiology of injuries in judo: a cross-sectional survey of severe injuries based on time loss and reduction in sporting level. Br J Sports Med 2018;52:1109-15.

6 Pierantozzi E. Judo high level competitions injuries. Medit J Musc Surv 2009;17:26-9.

7 TNO. Blessures judo en jiu-jitsu (BIS). TNO Kennis Voor Zaken 2018;21:38-42.

8 Raysmith B, Drew M. Performance success or failure is influenced by weeks lost to injury and illness in elite Australian track and field athletes: a 5-year prospective study. J Sci Med Sport 2016;19:778-83.

9 Lohmander L, Englund P, Dahl L, et al. The long-term consequence of anterior cruciate ligament and meniscus injuries: osteoarthritis. Am $J$ Sports Med 2007;35:1756-69.

10 Vriend I, Gouttebarge V, Finch CF, et al. Intervention strategies used in sport injury prevention studies: a systematic review identifying studies applying the Haddon matrix. Sport Med 2017;47:2027-43.

11 Schiff M, O'halloran R, Schiff M, et al. Injury prevention in sports. Am $J$ Lifestyle Med 2010;4:42-64.

12 Bizzini M, Dvorak J. FIFA 11+: an effective programme to prevent football injuries in various player groups worldwide - a narrative review. Br J Sports Med 2015;49:577-9.

13 Leppänen M, Aaltonen S, Parkkari J, et al. Interventions to prevent sports related injuries: a systematic review and meta-analysis of randomised controlled trials. Sport Med 2014;44:473-86.

14 Verhagen E, Voogt N, Bruinsma A, et al. A knowledge transfer scheme to bridge the gap between science and practice: an integration of existing research frameworks into a tool for practice. Br J Sports Med 2014;48:698-701.

15 Malliaropoulos N, Callan M, Johnson J. Comprehensive training programme for judo players nine plus 9+. Muscles Ligaments Tendons J 2014;4:262-8.

16 VJF (Vlaamse Judo Federatie). Available https://www.vjf.be/nl/clubs/ projecten/gezond-ethisch-sporten/ongevallenpreventie-het-judo (accessed 26 Feb 2019)

17 Verhagen E. If athletes will not adopt preventive measures, effective measures must adopt athletes. Am Coll Sports Med 2012;7-8.

18 Finch $C$. A new framework for research leading to sports injury prevention. J Sci Med Sport 2006;9:3-9.

19 Van Tiggelen D, Wickes S, Stevens V, et al. Effective prevention of sports injuries: a model integrating efficacy, efficiency, compliance and risk- taking behaviour. Br J Sports Med 2008;42:648-52.

20 Pas HIMFL, Bodde S, Kerkhoffs GMMJ, et al. Systematic development of a tennis injury prevention programme. BMJ Open Sport Exerc Med 2018;4:e000350.

21 Gouttebarge V, Zuidema V. Prevention of musculoskeletal injuries in recreational field hockey: the systematic development of an intervention and its feasibility. BMJ Open Sport Exerc Med 2018;4: e000425.
22 Minghelli B, Isidoro R. Prevalence of injuries in Jiu-Jitsu and Judo athletes of Portugal South: associated injury mechanisms. J Community Med Health Educ 2016;6(3).

23 James G, Pieter W. Injury rates in adult elite judoka. Biol Sport 2003;20:25-32.

24 Green CM, Petrou MJ, Fogarty-Hover MLS, et al. Injuries among judokas during competition. Scand J Med Sci Sport 2007.

25 Junge A, Engebretsen L, Mountjoy ML, et al. Sports injuries during the Summer Olympic Games 2008. Am J Sports Med 2009;37:2165-72.

26 Gal JSI, van der Made AD, Kneepkens HE, et al. Sporttraumatologie in het judo. Ned Tijdschr Voor Traumatol 2013;21:63-8.

27 Pocecco E, Ruedl G, Stankovic N, et al. Injuries in judo: a systematic literature review including suggestions for prevention. $\mathrm{Br} J$ Sports Med 2013;47:1139-43.

28 Kujala UM, Taimela S, Antti-Poika I, et al. Acute injuries in soccer, ice hockey, volleyball, basketball, judo, and karate: analysis of national registry data. Br Med J 1995;311:1465-8.

29 Jäggi U, Joray CP, Brülhart $Y$, et al. Verletzungen in den Kampfsportarten Judo, Taekwondo und Ringen - Eine systematische Übersichtsarbeit. Sportverletzung-Sportschaden 2015.

30 Racinais S, Cocking S, Périard JD, Racinais S, Cocking S, et al. Sports and environmental temperature: from warming-up to heating-up. Temperature 2017;4:227-57.

31 Kamitani T, Malliaropoulos NG, Omiya M, et al. On the way to the Tokyo Summer Olympic Games (2020). Prevention of severe head and neck injuries in judo: it's time for action. Br J Sports Med 2017;51:1581-2.

32 Sewry N, Verhagen E, Lambert M, et al. Evaluation of the effectiveness and implementation of the BokSmart Safe Six injury prevention programme : a study protocol. Inj Prev 2017;23:428.

33 Van Mechelen W, Hlobil H, Kemper HCG, Kemper HC, et al. Prevention of running injuries by warm-up, cool-down, and stretching exercises. Am J Sports Med 1993;21:711-9.

34 Buist I, Bredeweg SW, Van Mechelen W, et al. No effect of a graded training program on the number of running-related injuries a randomized controlled trial. Am J Sports Med 2008;(2):33-39.

35 Bredeweg SW, Zijlstra S, Bessem B, et al. The effectiveness of a preconditioning programme on preventing running-related injuries in novice runners: a randomised controlled trial. $\mathrm{Br} J$ Sports Med 2012;46:865-70.

36 Small K, Naughton LM, Matthews M, et al. A systematic review into the efficacy of static stretching as part of a warm-up for the prevention of exercise-related injury. Res Sports Med 2008;16:213-31.

37 Van Reijen M, Vriend I, Van Mechelen W, et al. Compliance with sport injury prevention interventions in randomised controlled trials: a systematic review. Sport Med 2016;46:1125-39.

38 Goode AP, Reiman MP, Harris L, et al. Eccentric training for prevention of hamstring injuries may depend on intervention compliance: a systematic review and meta-analysis. Br J Sports Med 2015;49:349-56.

39 Pasanen K, Parkkari J, Pasanen M, et al. Neuromuscular training and the risk of leg injuries in female floorball players: cluster randomised controlled study. Br J Sports Med 2008;42:502-5.

40 Olsen OE, Myklebust G, Engebretsen L, et al. Exercises to prevent lower limb injuries in youth sports: cluster randomised controlled trial. Br Med J 2005;330:449-52. 